\title{
Licensing Strategy for a Stochastic R\&D firm in a Differentiated Cournot Duopoly Model
}

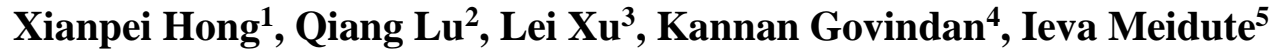 \\ ${ }^{1}$ College of Economics \& Management \\ Huazhong Agricultural University, Wuhan 430070, China \\ E-mail.xphong@mail.hzau.edu.cn \\ ${ }^{2}$ The University of Sydney, Sydney NSW 2006, Australia \\ E-mail.steven.lu@sydney.edu.au \\ ${ }^{3}$ Tianjin University of Technology \\ Tianjin 300384, P.R. China \\ E-mail.chully.xu@gmail.com \\ ${ }^{4}$ University of Southern Denmark \\ Denmark DK-5230 Odense M, Denmark \\ E-mail.gov@sam.sdu.dk \\ ${ }^{5}$ Vilnius Gediminas Technical University \\ Sauletekio av. 11, LT-10223, Vilnius, Lithuania \\ E-mail.ieva.meidute@vgtu.lt
}

cross $^{\text {ref }}$ http://dx.doi.org/10.5755/j01.ee.26.5.12313

Nowadays firms are increasingly licensing out technology, either as an outside licensor or as an inside licensor. However, extant literature on firm's technology innovation usually assumes that the R\&D outcome is certain, which does not hold in many real-world situations. To fill this gap, this paper investigates an innovating firm's licensing strategy in a differentiated Cournot duopoly model when the firm is an insider and the R\&D outcome is stochastic. We develop a duopoly game model in which the innovating firm has three options for licensing its innovation: fixed-fee licensing, royalty licensing and two-part tariff licensing. We consider three stages in the model: the R\&D, licensing and output stages. We find that product differentiation and technology spillover play significant roles in the innovating firm's choice between fixed-fee and royalty licensing. In addition, regardless of the degree of product differentiation, we find that (1) two-part tariff licensing is superior to both fixed-fee and royalty licensing when technology spillover is low and that (2) two-part tariff licensing is equivalent to royalty licensing when technology spillover is high.

Keywords: Technology licensing, R\&D Outcome, Licensing Options, Technology Spillover, Differentiated Cournot Duopoly, Game theory.

\section{Introduction}

R\&D uncertainty and high risk are two problems that both innovating firms and R\&D institutions regularly confront in practice. The former refers to high stochastic $R \& D$ outcomes and the high probability of $R \& D$ failure, which can result in substantial losses for innovators; the latter involves the possibility that the results of successful R\&D cannot be successfully commercialized and converted to use. Thus, technology licensing is a crucial component of technology commercialization strategies that exerts an important influence on improving products' market competitiveness, increasing innovation incentives and enhancing innovation capabilities. Moreover, the past 30 years have witnessed significant growth in global technology trade (Arora, 2009), and an increasing number of firms are now transferring rights to various technologies through licensing agreements (Arora et al., 2013). For example, in the computer industry, IBM made $\$ 1.3$ billion profit by licensing out its patents in 2000 (i.e., $10 \%$ of its pretax profits). In the semiconductor industry, Texas Instruments earns $\$ 40$ million annually from patent licensing (Germerad, 2001).

Technology transfer via licensing benefits both licensors and licensees. On the one hand, licensees who obtain new technology through licensing can improve their market competitiveness by closing the technology gap with licensors (Laursen et al., 2010; Tsai et al., 2011; Leone \& Reichstein, 2012; Wang et al., 2015). On the other hand, licensors - who often require a high level of investment to engage in technology innovation - can maximize the value of new technology generated by successful $R \& D$ via various licensing strategies that provide financial support for further innovation. The average annual yield of technology innovation is $40 \%$, which is much higher than the average annual yield of common investment-8\% (Griliches, 1992).

In the following, we will briefly outline the extant 
technology licensing literature.

The literature on technology licensing strategy has primarily developed along two lines. One stream of the literature examines optimal licensing strategies for outside innovators (e.g., Mukherjee, 2010; Li \& Wang, 2010; Kishimoto et al., 2011; Rey \& Salant, 2012; Chang et al., 2013; Bagchi \& Mukherjee, 2014). For example, Mukherjee (2010) introduces unions to the research and classifies these by whether they have centralized or decentralized structures. The result shows that as long as the union has full bargaining power (i.e., a monopoly union; see (Leahy \& Montagna, 2000; Haucap \& Wey, 2004), royalty licensing is superior to the other two strategies in spite of the union structure for outside innovators. (Kishimoto et al., 2011) study asymptotic bargaining outcomes when licensing a patented technology from an outside innovator to firms in a general Cournot structure. (Chang et al., 2013) consider a vertically related market structure in which the outside patentee licenses a cost-reducing technology to one or both downstream firms through either a fixed-fee or royalty licensing agreement.

Moreover, many studies examine firms' optimal licensing strategies from the perspective of information structure by investigating the outside innovator's optimal licensing strategy under incomplete information (see Gallini \& Wright, 1990; Poddar \& Sinha, 2002; Sen, 2005). For example, (Sen, 2005) considers the outside innovator's licensing problem with an incumbent monopoly under incomplete information and argues that diversification in optimal licensing mechanisms results from incomplete information regarding the incumbent monopoly firm's cost, which might be one reason for the coexistence of a variety of licensing mechanisms in practice.

The second stream of the literature examines the inside innovator's optimal licensing strategy (e.g., Wang, 2002; Mittendorf \& Arya, 2006; Wang et al., 2013; Ferreira \& Bode, 2013; Lu \& Poddar, 2014; Zhao et al., 2014; Chen et al., 2014; Ghosh \& Saha, 2015; Colombo \& Filippini, 2015). For example, (Wang, 2002) compares fixed-fee licensing and royalty licensing in homogeneous and differentiated Cournot duopolies, respectively. (Mittendorf \& Arya, 2006) show that a producer-innovator's patent licensing cannot only benefit the licensor, but can benefit other supply chain members (the supplier, licensee, and consumers). (Wang et al., 2013) extend the results from (Poddar \& Sinha, 2010) to an oligopolistic model consisting of three cost differential firms in a Cournot framework to explore optimal licensing strategies.

In addition, the previous literature - including (Filippini, 2005; Kabiraj, 2005; Erkal, 2005; Mukherjee \& Pennings, 2006) - attempts to indentify the incumbent innovating firm's optimal licensing strategy by proceeding from the enterprise's competition pattern. (Filippini, 2005; Kabiraj, 2005) employ a Stackelberg competitive model and argue that royalty licensing is always superior to fixed-fee licensing. However, both (Erkal, 2005; Mukherjee \& Pennings, 2006; focus on a Bertrand competitive market and find that the degree of product substitution and the innovation scale play a vital role in the optimal licensing strategy, regardless of the competitive model.

A common feature of the studies described above is that they assume that the R\&D outcome is certain and that there is no technology spillover ${ }^{1}$. In practice, however, it is frequently the case that the outcome is inclined to be stochastic to some degree and that there is technology spillover, which may have an important impact on the optimal licensing strategy. However, the literature to date has not focused on uncovering the relationship between R\&D outcome uncertainty and technology licensing, which is an important element of conduct in many industries. Theoretical interest in this paper arises from the fact that no other work to date has discussed the problem under $R \& D$ outcome uncertainty.

In this paper, the innovator is an insider and the product market has a differentiated Cournot duopoly structure. The innovator has a cost-reducing innovation and three substitutive licensing policies, namely, fixed-fee licensing, royalty licensing and two-part tariff licensing. We assume that the licensor makes a take-it-or-leave-it offer to the licensee, and the licensee is assumed to accept the license when it is indifferent as to whether to license (or not) or when it achieves a higher payoff by licensing.

The primary purpose of this paper is to explore the following two issues by considering a stochastic R\&D process for the innovator when the innovator is an insider patentee as firms produce a differentiated product and engage in Cournot competition. First, this paper seeks to determine the stochastic R\&D firm's optimal licensing policy (i.e., fixed-fee licensing, royalty licensing or two-part tariff licensing). Second, this paper attempts to ascertain the effects of product differentiation and technology spillover on the optimal licensing policy for the innovating firm.

We develop a duopoly game model with three stages: (1) the R\&D stage, in which the firm engages in a cost-reducing innovation with a success probability of $p$;

(2) the licensing stage, in which the innovating firm can either protect its technology patent or allow another firm to adopt its technology (if the innovating firm does not license its technology, it will become a monopoly, and if the innovating firm decides to license its technology to another firm, it must determine a reasonable and acceptable price for the licensee); and (3) the output stage, in which the licensor and the licensee compete in the product market in a Cournot competition.

This paper contributes to the literature in several ways. First, we study the innovator's optimal licensing strategy

\footnotetext{
${ }^{1}$ Technology spillover, which is a positive externality, is a phenomenon in which other firms obtain access to the technology of the innovating firm for free or at low cost. As an exogenous variable, technology spillover is primarily determined by the level of intellectual property protection; as an endogenous variable, it is dependent on the complexity of the technology itself and the innovating firm's strategy. Technology spillover is discussed by (D'Aspremont and Jacquemin 1988; Kamien et al., 1992). Generally speaking, there is typically a negative correlation between technology spillover and imitation complexity. In other words, if technology spillover is high, the imitation process is comparatively easy (low imitation cost); otherwise, it is difficult to imitate. Please see (Mansfield, 1985) for details. In this paper, technology spillover is set as an exogenous variable and acts as a proxy for imitation complexity.
} 
under uncertain R\&D outcome conditions. However, the extant literature discusses the optimal licensing strategy only under the condition that R\&D is successful, without considering a stochastic outcome. Second, we examine the impact of both product differentiation and technology spillover on the innovator's licensing strategy, whereas the extant literature focuses primarily on the former (e.g., Wang, 2002; Ferreira \& Bode, 2013), and less research centers on technology spillover. To the best of our knowledge, this paper is the first to explore the joint influence of product differentiation and technology spillover on licensing strategy. Third, we illustrate that the amount of $R \& D$ investment is also closely related to the innovator's choice of licensing policy.

This paper is organized as follows. Section 2 describes the model. In Section 3, we address the case of non-licensing as a benchmark. We present the model and investigate three licensing policies in Section 4. Section 5 analyses the optimal licensing strategy from the perspective of the innovator. Finally, we conclude our paper in Section 6. All technical proofs are provided in the appendix.

\section{Modeling Assumptions}

We consider a quantity competition model in which two downstream firms (firm $i$ and firm $j$ ) conduct a Cournot competition game and two firms produce differentiated products in the same market. Suppose firm $i$ can achieve a licensable innovation, but the $\mathrm{R} \& \mathrm{D}$ outcome is uncertain. The other firm, firm $j$, does not produce anything innovative. Consistent with Wang (2002), we assume that the linear inverse demand functions are $P_{i}=a-\left(q_{i}+d q_{j}\right), P_{j}=a-\left(d q_{i}+q_{j}\right)$, where $P_{i}$ and $P_{j}$ represents firm $i$ 's and firm $j$ 's market prices, respectively, and $q_{i}$ and $q_{j}$ denote firm $i$ 's and firm $j$ 's outputs, respectively. As the substitution coefficient, $d$ satisfies $d \in(0,1)$. The smaller $d$ is, the more different the two products are, and vice versa. When $d$ becomes closer to 1 , the two products are closer substitutes. We assume that the two firms share the same technology level at the initial stage and have the same constant marginal cost, $c$. Before the output stage, firm $i$ carries out cost-reducing innovation independently with probability $p$ of succeeding, which reduces its marginal cost from $c$ to 0 . The required $\mathrm{R} \& \mathrm{D}$ investment is $k p^{2}$, where $k>0$ and represents the unit cost of $\mathrm{R} \& \mathrm{D}$ or $\mathrm{R} \& \mathrm{D}$ efficiency, which conforms to the law of diminishing returns. As a result of technology spillover, if firm $i$ succeeds in $\mathrm{R} \& \mathrm{D}$, firm $j$ can lower its marginal cost from $c$ to $(1-\beta) c$, where $\beta \in[0,1]$ denotes the degree of technology spillover. The marginal cost of both firms will remain $c$ if firm $i$ fails in R\&D.

Technology innovation can be divided into drastic and non-drastic innovations in accordance with the magnitude of the innovation. With a drastic innovation, the innovating firm can expel other firms from the market that have only the old technology if licensing does not occur. Otherwise, the innovation is non-drastic. In other words, without licensing, innovators with a drastic innovation will monopolize the market, whereas those with a non-drastic innovation must confront market competition. This paper focuses solely on the condition of non-drastic innovation for simplicity; however, drastic innovation problems can be solved in a similar manner.

When technology licensing occurs between the two firms, we consider the following three-stage game. In the first stage, firm $i$ chooses value $p$ to determine the optimal R\&D investment. In the second stage, if firm $i$ succeeds in $R \& D$, it will decide whether to license the new technology to firm $j$, while the latter can choose to accept or reject the license. In the third stage, firm $i$ and firm $j$ engage in a Cournot competition in the product market. While optimizing their objective functions, we assume that both of the two firms have access to the same information. We use backward induction to solve this problem.

We first study the case without technology licensing to perform a comparative analysis with the following three licensing policies.

\section{Benchmark Model: No Licensing}

In the case of an uncertain $R \& D$ outcome, there are two possible reasons for firm $i$ not to license: failure in $R \& D$ or unwillingness to license with successful R\&D. We illustrate these two situations below.

\section{Successful R\&D But no Licensing}

In the output stage, firm $i$ and firm $j$ engage in output Cournot competition. When firm $i$ succeeds in $\mathrm{R} \& \mathrm{D}$ before licensing with a probability of $p$, the marginal cost for firm $i$ is 0 , whereas for firm $j$, it is $c_{j}=(1-\beta) c$. The two firms' optimal problems can be expressed by

$$
\begin{aligned}
\operatorname{Max}_{q_{i}} \pi_{i}^{S} & =\left[a-\left(q_{i}+d q_{j}\right)\right] q_{i}-k p^{2}, \\
\operatorname{Max}_{q_{j}} \pi_{j}^{S} & =\left[a-\left(d q_{i}+q_{j}\right)-(1-\beta) c\right] q_{j}
\end{aligned}
$$

where superscript $S$ denotes successful R\&D without licensing.

By solving the above problems, we can further obtain the two firms' equilibrium quantities:

$$
q_{i}^{S}=\frac{(2-d) a+d(1-\beta) c}{(2+d)(2-d)}, q_{j}^{S}=\frac{(2-d) a-2(1-\beta) c}{(2+d)(2-d)}
$$

$q_{j}^{s}>0$ will always be true because of non-drastic innovation. Substituting Eq. (2) into Eq. (1), we obtain the equilibrium profits of the two firms when R\&D is successful but does not lead to licensing.

$$
\pi_{i}^{S}=\frac{[(2-d) a+d(1-\beta) c]^{2}}{(2+d)^{2}(2-d)^{2}}-k p^{2}, \quad \pi_{j}^{S}=\frac{[(2-d) a-2(1-\beta) c]^{2}}{(2+d)^{2}(2-d)^{2}}
$$

\section{Failure in $R \& D$}

If the innovation process ends in failure, the marginal costs for the two firms remain $c_{i}=c_{j}=c$ with a probability of $1-p$. The profit functions in this condition for firm $i$ and firm $j$ are given as 
Xianpei Hong, Qiang Lu, Lei Xu, Kannan Govindan, Ieva Meidute. Licensing Strategy for a Stochastic R\&D firm in ...

$\pi_{i}^{N}=\left[a-\left(q_{i}+d q_{j}\right)-c\right] q_{i}-k p^{2}$,

$\pi_{j}^{N}=\left[a-\left(d q_{i}+q_{j}\right)-c\right] q_{j}$

where superscript $N$ denotes that R\&D ends in failure.

We can obtain the two firms' equilibrium quantities by optimizing Eq. (4):

$$
q_{i}^{N}=(a-c) /(2+d), \quad q_{j}^{N}=(a-c) /(2+d)
$$

Substitute Eq. (5) into Eq. (4), and equilibrium profits can be obtained:

$$
\pi_{i}^{N}=(a-c)^{2} /(2+d)^{2}-k p^{2}, \quad \pi_{j}^{N}=(a-c)^{2} /(2+d)^{2}(6)
$$

Then, we can derive the two firms' expected profits according to Eq. (3) and Eq. (6).

$$
\begin{aligned}
& \pi_{\mathrm{i}}^{E}(p)=p \frac{[(2-d) a+d(1-\beta) c]^{2}}{(2+d)^{2}(2-d)^{2}}+(1-p) \frac{(a-c)^{2}}{(2+d)^{2}}-k p^{2} \\
& \text { and } \pi_{\mathrm{j}}^{E}(p)=p \frac{[(2-d) a-2(1-\beta) c]^{2}}{(2+d)^{2}(2-d)^{2}}+(1-p) \frac{(a-c)^{2}}{(2+d)^{2}}
\end{aligned}
$$

\section{Main Model}

\section{Fixed-fee Licensing}

In this subsection, we consider licensing by means of a fixed fee only. Under fixed-fee licensing, firm $i$ licenses its new technology to firm $j$ at a fixed-fee, $F$, whose price is irrelevant to the quantity of product that firm $j$ will produce by applying the new technology.

\section{The Output Stage}

If firm $i$ succeeds in R\&D with probability $p$ in the first stage of the game, but licensing occurs in the second stage, the two firms will share the same technology level with marginal costs satisfying $c_{i}=c_{j}=0$. Firm $j$ offers a one-off payment of the amount $F$ to firm $i$. The two firms' profit functions are given by

$$
\begin{aligned}
& \pi_{i}^{F}=\left[a-\left(q_{i}+d q_{j}\right)\right] q_{i}-k p^{2}+F \\
& \pi_{j}^{F}=\left[a-\left(d q_{i}+q_{j}\right)\right] q_{j}-F
\end{aligned}
$$

where $F$ denotes the case of fixed-fee licensing.

The two firms' equilibrium quantities are given by

$$
q_{i}^{F}=a /(2+d), q_{j}^{F}=a /(2+d) .
$$

Equilibrium profits can be obtained by substituting Eq. (8) into Eq. (7):

$$
\begin{aligned}
& \pi_{i}^{F}=a^{2} /(2+d)^{2}-k p^{2}+F \text { and } \\
& \pi_{j}^{F}=a^{2} /(2+d)^{2}-F .
\end{aligned}
$$

If firm $i$ fails in $\mathrm{R} \& \mathrm{D}$, the equilibrium quantities and equilibrium profits are given by Eq. (5) and Eq. (6), respectively.

\section{The Licensing stage}

If firm $i$ succeeds in $\mathrm{R} \& \mathrm{D}$ with a probability of $p$ and fixed-fee licensing occurs, firm $i$ 's optimization problem is represented as follows.

$$
\begin{aligned}
& \operatorname{Max}_{F} \pi_{i}^{F} \\
& \text { s.t. } \pi_{j}^{F} \geq \pi_{j}^{S}
\end{aligned}
$$

Supposing that firm $i$ has full bargaining power, i.e., firm $i$ can obtain all the additional payoff of firm $j$, the maximum fixed fee is then

$$
F=a^{2} /(2+d)^{2}-[(2-d) a-2(1-\beta) c]^{2} /(2+d)^{2}(2-d)^{2}
$$

After fixed-fee licensing, the additional profits for the two firms are $\Delta \pi_{i}=\pi_{i}^{F}-\pi_{i}^{S}$ and $\Delta \pi_{j}=\pi_{j}^{F}-\pi_{j}^{S}$, which can be further simplified to

$$
\begin{gathered}
\Delta \pi_{i}=\frac{2(2-d)^{2} a^{2}-[(2-d) a+d(1-\beta) c]^{2}-[(2-d) a-2(1-\beta) c]^{2}}{(2+d)^{2}(2-d)^{2}} \\
\text { and } \Delta \pi_{j}=0
\end{gathered}
$$

Corollary 1. When firm $i$ succeeds in $R \& D$ for $d \in(0,0.8284)$, fixed-fee licensing will always occur despite the degree of technology spillover; for $d \in[0.8284,1)$, fixed-fee licensing occurs only if the technology spillover is high, i.e., $\beta \geq \beta_{1}^{*}=1-2 a(2-d)^{2} / c\left(4+d^{2}\right)$.

Corollary 1 shows that in the case of non-drastic innovation and an uncertain $R \& D$ outcome, the innovator prefers to license its technology by means of a fixed fee if the products from the two firms are substantially different; otherwise, the innovator is motivated to license via a fixed fee only if the technology spillover is high.

\section{The R\&D Stage}

In the first stage of the game, firm $i$ chooses the value of $p$ to decide the optimal $\mathrm{R} \& \mathrm{D}$ investment to maximize its expected profits. Substituting Eq. (11) into Eq. (9), we can obtain the profit of firm $i$ when $R \& D$ is successful and fixed-fee licensing occurs:

$$
\pi_{i}^{F}=\frac{2(2-d)^{2} a^{2}-[(2-d) a-2(1-\beta) c]^{2}}{(2+d)^{2}(2-d)^{2}}-k p^{2}
$$

Then, for a failure in $\mathrm{R} \& \mathrm{D}$ with a probability of $1-p$, fixed-fee licensing will not occur, and the two firms' profits are given by Eq. (6). We establish $\pi_{i}^{E F}(p)$ to express the expected profit for fixed-fee licensing:

$$
\pi_{i}^{E F}(p)=p \frac{2(2-d)^{2} a^{2}-[(2-d) a-2(1-\beta) c]^{2}}{(2+d)^{2}(2-d)^{2}}+(1-p) \frac{(a-c)^{2}}{(2+d)^{2}}-k p^{2}(13)
$$

where the superscript $E F$ denotes the expected value for fixed-fee licensing.

We take the first-order derivative of $\pi_{i}^{E F}(p)$ with respect to $p$ and obtain

$$
p^{F}=\frac{2(2-d)^{2} a^{2}-[(2-d) a-2(1-\beta) c]^{2}-(2-d)^{2}(a-c)^{2}}{2(2+d)^{2}(2-d)^{2} k}
$$

\section{Royalty Licensing}

In this subsection, we consider licensing by means of a royalty only. Under royalty licensing, firm $i$ licenses its cost-reducing technology to firm $j$ at a fixed royalty rate, $r$, and firm $i$ will gain a royalty amount that depends on firm $j$ 's production quantity applying the new technology.

\section{The Output Stage}

In the output stage, firm $i$ and firm $j$ engage in an output Cournot competition. Due to the uncertainty of $\mathrm{R} \& \mathrm{D}$, if firm $i$ succeeds in R\&D in the first stage and royalty licensing occurs, the two firms will share the same 
technology level, with the marginal costs for firm $i$ and firm $j$ being $c_{i}=0$ and $c_{j}=r$, respectively. It is easy to find that the two firms do not produce at the same marginal cost, which results from firm $i$ 's royalty distorting firm $j$ 's marginal cost. The two firms' profit functions are given by

$$
\begin{aligned}
& \pi_{i}^{R}=\left[a-\left(q_{i}+d q_{j}\right)\right] q_{i}-k p^{2}+r q_{j}, \\
& \pi_{j}^{R}=\left[a-\left(d q_{i}+q_{j}\right)-r\right] q_{j}
\end{aligned}
$$

licensing.

where superscript $R$ denotes the case of royalty

The two firms' equilibrium quantities are given by

$q_{i}^{R}=[(2-d) a+d r c] /\left(4-d^{2}\right)$ and

$q_{j}^{R}=[(2-d) a-2 r] /\left(4-d^{2}\right)$

Equilibrium profits can be obtained by substituting Eq. (16) into the profit function Eq. (15).

$$
\begin{aligned}
& \pi_{i}^{R}=\frac{[(2-d) a+d r]^{2}}{(2+d)^{2}(2-d)^{2}}+\frac{[(2-d) a-2 r]}{(2+d)(2-d)} r-k p^{2} \text { and } \\
& \pi_{j}^{R}=\frac{[(2-d) a-2 r]^{2}}{(2+d)^{2}(2-d)^{2}}
\end{aligned}
$$

If firm $i$ fails in R\&D considering the uncertainty of the outcome, equilibrium profits are given by Eq. (6).

\section{The Licensing Stage}

If firm $i$ succeeds in $\mathrm{R} \& \mathrm{D}$ with probability $p$ and royalty licensing occurs, firm $i$ 's optimization problem is represented as follows.

$$
\begin{aligned}
& \operatorname{Max}_{r} \pi_{i}^{R} \\
& \text { s.t. } \quad \pi_{j}^{R} \geq \pi_{j}^{S}
\end{aligned}
$$

which indicates that the optimal royalty rate should maximize firm $i$ 's profit on the premise that firm $j$ accepts royalty licensing.

$\pi_{j}^{S}$ has been given by Eq. (2), and we can obtain the condition under which firm $i$ asks for the royalty rate by solving the following inequality:

$$
\frac{[(2-d) a-2 r]^{2}}{(2+d)^{2}(2-d)^{2}}-\frac{[(2-d) a-2(1-\beta) c]^{2}}{(2+d)^{2}(2-d)^{2}} \geq 0
$$

Because we assume that firm $i$ has full bargaining power, the maximum royalty rate that firm $i$ can charge is $r_{1}=(1-\beta) c$. Take the partial derivative of $\pi_{i}^{R}$ in Eq. (17) with respect to $r$ without considering whether firm $j$ accepts, and from the first-order condition, we can obtain

$r_{2}=(2-d)\left(4+2 d-d^{2}\right) a / 2\left(8-3 d^{2}\right)$

However, the optimal royalty rate should be $r=\min \left(r_{1}, r_{2}\right)$ because when $r_{2}<r_{1}$, firm $i$ will be more profitable when charging $r_{2}$ instead of $r_{1}$; when $r_{2} \geq r_{1}$, firm $i$ must choose $r_{1}$ considering firm $j$ 's acceptance constraint.

We first assume that $r_{2}>r_{1}$ to compare $r_{1}$ and $r_{2}$. If

$r_{2}-r_{1}=(2-d)\left(4+2 d-d^{2}\right) a / 2\left(8-3 d^{2}\right)-(1-\beta) c \geq 0$, then $\beta \geq 1-(2-d)\left(4+2 d-d^{2}\right) a / 2 c\left(8-3 d^{2}\right), \quad$ which meets the prerequisites for non-drastic innovation.
Therefore, when;

$\beta \geq 1-(2-d)\left(4+2 d-d^{2}\right) a / 2 c\left(8-3 d^{2}\right), \quad r_{2}>r_{1}$, we obtain the optimal royalty rate $r=(1-\beta) c$, and when $\beta<1-(2-d)\left(4+2 d-d^{2}\right) a / 2 c\left(8-3 d^{2}\right), r_{2}<r_{1}$, we obtain the optimal royalty rate;

$$
r=(2-d)\left(4+2 d-d^{2}\right) a / 2\left(8-3 d^{2}\right) \text {. }
$$

Thus, we can obtain Corollary 2 to determine whether royalty licensing will occur.

Corollary 2. If firm $i$ succeeds in $R \& D$ with probability $p$, royalty licensing will always occur when the condition for implementing royalty licensing is met.

According to Corollary 2, firm $i$ will always choose to license by means of royalty in the case of non-drastic innovation regardless of the degree of technology spillover and product substitution.

\section{The $R \& D$ stage}

In this stage, firm $i$ chooses a value of $p$ to decide the optimal R\&D investment to maximize expected profits. When $R \& D$ is successful with probability $p$, the expected profits and probability of success are related to the degree of technology spillover.

$$
\begin{gathered}
\text { When } \quad \beta \geq 1-(2-d)\left(4+2 d-d^{2}\right) a / 2 c\left(8-3 d^{2}\right), \\
\pi_{i}^{E R}(p)=p\left\{\frac{[(2-d) a+d(1-\beta) c]^{2}}{(2+d)^{2}(2-d)^{2}}+\frac{(1-\beta) c[(2-d) a-2(1-\beta) c]}{(2+d)(2-d)}\right\}+(1-p) \frac{(a-c)^{2}}{(2+d)^{2}}-k p^{2}
\end{gathered}
$$

where superscript $E R$ denotes the expected value in the case of royalty licensing.

We take the first-order derivative of $\pi_{i}^{E F}(p)$ with respect to $p$ and obtain

$$
\begin{gathered}
p^{R}=\frac{[(2-d) a+d(1-\beta) c]^{2}+(2+d)(2-d)[(2-d) a-2(1-\beta) c](1-\beta) c-(2-d)^{2}(a-c)^{2}}{2(2+d)^{2}(2-d)^{2} k}(22) \\
\text { When } \beta<1-(2-d)\left(4+2 d-d^{2}\right) a / 2 c\left(8-3 d^{2}\right), \\
\pi_{i}^{E R}(p)=p \frac{\left[\left(4+2 d-d^{2}\right)^{2}+4\left(8-3 d^{2}\right)^{2}\right] a^{2}}{4\left(8-3 d^{2}\right)^{2}(2+d)^{2}}+(1-p) \frac{(a-c)^{2}}{(2+d)^{2}}-k p^{2}(23
\end{gathered}
$$

where superscript $E R$ denotes the expected value in the case of royalty licensing.

We take the first-order derivative of $\pi_{i}^{E F}(p)$ with respect to $p$ and obtain

$$
p^{R}=\frac{\left[\left(4+2 d-d^{2}\right)^{2}+4\left(8-3 d^{2}\right)^{2}\right] a^{2}}{8\left(8-3 d^{2}\right)^{2}(2+d)^{2} k}-\frac{(a-c)^{2}}{2(2+d)^{2} k}
$$

\section{Two-Part Tariff Licensing}

In this subsection, we consider licensing by means of a hybrid license consisting of a fixed-fee $(F)$ and a per unit royalty $(r)$. Under two-part tariff licensing, the total licensing fee that firm $i$ charges is $F+r q_{j}$, where $F \geq 0$ and $r \geq 0$. Because the feasible region for two-part tariff licensing overlaps those of royalty licensing $(F=0)$ and fixed-fee licensing $(r=0)$, the optimal policy in two-part tariff licensing can involve either single royalty licensing or single fixed-fee licensing.

When licensing occurs, firm $i$ 's unit production cost is zero, and firm $j$ 's unit production cost is $r$. 
Xianpei Hong, Qiang Lu, Lei Xu, Kannan Govindan, Ieva Meidute. Licensing Strategy for a Stochastic R\&D firm in ...

\section{The Output Stage}

In this stage, if firm $i$ succeeds in $\mathrm{R} \& \mathrm{D}$ with probability $p$ in the first stage and licenses by means of a two-part tariff, the two firms' profit functions are

$$
\pi_{i}^{F R}=\left[a-\left(q_{i}+d q_{j}\right)\right] q_{i}+r q_{j}+F-k p^{2} \text { and }
$$$$
\pi_{j}^{F R}=\left[a-\left(d q_{i}+q_{j}\right)-r\right] q_{j}-F
$$

where superscript $F R$ denotes the case of two-part tariff licensing.

Their equilibrium quantities and equilibrium profits are as follows from Eq. (25).

$$
\begin{aligned}
q_{i}^{F R} & =\frac{(2-d) a+d r}{(2+d)(2-d)}, \quad q_{j}^{F R}=\frac{(2-d) a-2 r}{(2+d)(2-d)}, \\
\pi_{i}^{F R} & =\frac{[(2-d) a+d r]^{2}}{(2+d)^{2}(2-d)^{2}}+\frac{(2-d) a-2 r}{(2+d)(2-d)} r+F-k p^{2}, \\
\pi_{j}^{F R} & =\frac{[(2-d) a-2 r]^{2}}{(2+d)^{2}(2-d)^{2}}-F .
\end{aligned}
$$

If firm $i$ fails in $\mathrm{R} \& \mathrm{D}$, equilibrium profits are given by Eq. (6).

\section{The Licensing Stage}

If firm $i$ succeeds in $\mathrm{R} \& \mathrm{D}$, it will choose two-part tariff licensing to license its innovation. Firm $j$ can either accept or reject the licensing offer. Firm $i$ 's optimization problem is expressed as follows:

$$
\begin{aligned}
& \operatorname{Max}_{F, r} \pi_{i}^{F R} \\
& \text { s.t. } \pi_{j}^{F R} \geq \pi_{j}^{S}
\end{aligned}
$$

among which $\pi_{j}^{S}$ has been given by Eq. (3).

When firm $i$ has full bargaining power, the maximum fixed fee it can charge is

$$
F=[(2-d) a-2 r]^{2} /\left(4-d^{2}\right)^{2}-[(2-d) a-2(1-\beta) c]^{2} /\left(4-d^{2}\right)^{2}(29)
$$

Because $F \geq 0$, we can obtain the maximum per unit royalty within firm $j$ 's acceptance, i.e., $r_{j}=(1-\beta) c$.

Substitute $F$ into Eq. (18), and we obtain $\pi_{i}^{F R}=\frac{-\left(4-3 d^{2}\right) r^{2}+(2-d)^{2} d r+2(2-d)^{2} a^{2}-[(2-d) a-2(1-\beta) c]^{2}}{(2+d)^{2}(2-d)^{2}}-k p^{2}$

Take the partial derivative of Eq. (30) with respect to $r$, and from the first-order condition, we can obtain $r_{i}=a d(2-d)^{2} / 2\left(4-3 d^{2}\right)$.

We obtain the value of $r_{i}$, which can maximize firm $i$ 's profit without considering firm $j$ 's willingness to accept.

In fact, the optimal royalty rate $r^{*}$ in two-part tariff licensing should satisfy $r^{*}=\min \left(r_{i}, r_{j}\right)$. Therefore, we must compare $r_{i}$ with $r_{j}$.

According to the analysis, for $\beta \geq 1-a d(2-d)^{2} / 2 c\left(4-3 d^{2}\right) \quad, \quad r_{i} \geq r_{j} \quad$ and $r^{*}=r_{j}=(1-\beta) c ;$ for $\beta<1-a d(2-d)^{2} / 2 c\left(4-3 d^{2}\right)$, $r_{i}<r_{j} \quad$ and $\quad r^{*}=r_{i}=a d(2-d)^{2} / 2\left(4-3 d^{2}\right)$.

When $r^{*}=(1-\beta) c, \quad F=0$ and two-part tariff licensing is equivalent to royalty licensing. When $r^{*}=\operatorname{ad}(2-d)^{2} / 2\left(4-3 d^{2}\right)$,

$$
F=\frac{4(1-d)^{2} a^{2}}{\left(4-3 d^{2}\right)^{2}}-\frac{[(2-d) a-2(1-\beta) c]^{2}}{(2+d)^{2}(2-d)^{2}}>0 .
$$

Therefore, for $\beta<1-a d(2-d)^{2} / 2 c\left(4-3 d^{2}\right)$, firm $i$ 's profit is

$$
\pi_{i}^{F R}=\left(8-8 d+d^{2}\right) a^{2} / 4\left(4-3 d^{2}\right)-[(2-d) a-2(1-\beta) c]^{2} /\left(4-d^{2}\right)^{2}-k p^{2}(
$$

As shown in the above analysis, firm $j$ is always ready to accept two-part tariff licensing. The question is whether firm $i$ is willing to license its technology to firm $j$. Thus, we must find the conditions under which two-part tariff licensing occurs, and Corollary 3 can be generalized based on the comparison.

Corollary 3. In the case of non-drastic innovation, two-part tariff licensing is superior to no licensing if firm $i$ succeeds in $R \& D$ with probability $p$ and the technology spillover satisfies

$$
\beta<1-a d(2-d)^{2} / 2 c\left(4-3 d^{2}\right) \text {. }
$$

\section{The $R \& D$ Stage}

In this stage, firm $i$ determines its optimal $\mathrm{R} \& \mathrm{D}$ investment by choosing $p$ to maximize expected profit. If $\beta \geq 1-a d(2-d)^{2} / 2 c\left(4-3 d^{2}\right)$, two-part tariff licensing is equivalent to royalty licensing, which has been clarified in subsection 4.2. Next, we will discuss the condition in which $\beta<1-a d(2-d)^{2} / 2 c\left(4-3 d^{2}\right)$. We can obtain firm $i$ 's expected profit $\pi_{i}^{E F R}(p)$ by combining Eq. (31) and Eq. (6).

$\pi_{i}^{E F R}(p)=p \frac{\left(8-8 d+d^{2}\right) a^{2}}{4\left(4-3 d^{2}\right)}-p \frac{[(2-d) a-2(1-\beta) c]^{2}}{(2+d)^{2}(2-d)^{2}}+(1-p) \frac{(a-c)^{2}}{(2+d)^{2}}-k p^{2}$ where EFR denotes the expected value for the case of two-part tariff licensing.

Take the first-order partial derivative of Eq. (32) with respect to $p$, and from the first-order condition, we obtain

$$
p^{F R}=\frac{\left(8-8 d+d^{2}\right)(2+d)^{2}(2-d)^{2} a^{2}-4\left(4-3 d^{2}\right)[(2-d) a-2(1-\beta) c]^{2}}{8\left(4-3 d^{2}\right)(2+d)^{2}(2-d)^{2} k}-\frac{(a-c)^{2}}{2(2+d)^{2} k}
$$

\section{Optimal Licensing Decision}

In this section, we assume that all three licensing strategies are available to the innovator. In section 4 , we derived firm $i$ 's profits. To find firm $i$ 's optimal decision, we must compare the profits of firm $i$ under different licensing scenarios and choose the profit-maximizing strategy.

\section{Comparison: Fixed Fee Versus Royalty Licensing}

If both fixed-fee licensing and royalty licensing are available to the licensor, which is the better choice? To find the answer, we will compare the probability of occurrence and expected profits under these two situations.

$$
\begin{aligned}
& \text { If } \beta \geq 1-(2-d)\left(4+2 d-d^{2}\right) a / 2 c\left(8-3 d^{2}\right) \text {, then } \\
& p^{R}-p^{F}=\frac{\left(4-3 d^{2}\right)(1-\beta) c^{2}}{2(2+d)^{2}(2-d)^{2} k} \cdot\left\{\beta-\left[1-\frac{d(2-d)^{2}}{4-3 d^{2}} \cdot \frac{a}{c}\right]\right\}, \\
& \pi_{i}^{E R}(p)-\pi_{i}^{E F}(p)=\frac{\left(4-3 d^{2}\right)(1-\beta) c^{2}}{(2+d)^{2}(2-d)^{2}} \cdot\left\{\beta-\left[1-\frac{d(2-d)^{2}}{4-3 d^{2}} \cdot \frac{a}{c}\right]\right\} \\
& \text { If } \beta<1-(2-d)\left(4+2 d-d^{2}\right) a / 2 c\left(8-3 d^{2}\right) \text {, then }
\end{aligned}
$$


$p^{R}-p^{F}=\frac{-(2-d)^{2}\left(20+2 d-7 d^{2}\right)\left(12-2 d-5 d^{2}\right) a^{2}+4\left(8-3 d^{2}\right)^{2}[(2-d) a-2(1-\beta) c]^{2}}{8\left(8-3 d^{2}\right)^{2}(2+d)^{2} k}$,

$\pi_{i}^{E R}(p)-\pi_{i}^{E F}(p)=\frac{-(2-d)^{2}\left(20+2 d-7 d^{2}\right)\left(12-2 d-5 d^{2}\right) a^{2}+4\left(8-3 d^{2}\right)^{2}[(2-d) a-2(1-\beta) c]^{2}}{4\left(8-3 d^{2}\right)^{2}(2+d)^{2}}$

Proposition 1 will explain which licensing option is more likely to occur.

Proposition 1. In the case of a non-drastic innovation, the probability of occurrence of these two licensing policies is closely related to the degree of product substitution and technology spillover. Specifically,

(i) For $d \in(0,0.7280)$, when $\beta<\bar{\beta}$, then $p^{F}>p^{R}$; when $\beta>\bar{\beta}$, then $p^{F}<p^{R}$; and when $\beta=\bar{\beta}$ or $\beta=1$, then $p^{F}=p^{R}$;

(ii) For $d \in[0.7280,1)$, when $\beta<\hat{\beta}$, then $p^{F}>p^{R}$; when $\beta \geq \hat{\beta}$, then $p^{F}<p^{R}$; and when $\beta=1$, then $p^{F}=p^{R} \quad, \quad$ where $\quad \bar{\beta} \equiv 1-\operatorname{ad}(2-d)^{2} / c\left(4-3 d^{2}\right)$, $\hat{\beta} \equiv 1-a(2-d)\left(4+2 d-d^{2}\right) / 2 c\left(8-3 d^{2}\right)$.

Proposition 1 shows that $p$ can also reflect the R\&D investment $k p^{2}$ under different licensing scenarios. If $p^{F}>p^{R}$, the corresponding $\mathrm{R} \& \mathrm{D}$ investment in fixed-fee licensing is higher than that in royalty licensing; if $p^{F}<p^{R}$, the opposite is true; and if $p^{F}=p^{R}$, the two licensing scenarios share the same R\&D investment.

Comparing the related equations above, we find that the sign of Eq. (28) is the same as the sign of Eq. (29), which is also true for Eq. (27) and Eq. (28). Because $p^{F}$ and $p^{R}$ can maximize $\pi_{i}^{E F}(p)$ and $\pi_{i}^{E R}(p)$, respectively, if $\quad p^{F}>p^{R} \quad$, then $\pi_{i}^{E F}\left(p^{F}\right)>\pi_{i}^{E F}\left(p^{R}\right)>\pi_{i}^{E R}\left(p^{R}\right) ;$ if $p^{F}<p^{R}$, then $\pi_{i}^{E F}\left(p^{F}\right)<\pi_{i}^{E R}\left(p^{F}\right)<\pi_{i}^{E R}\left(p^{R}\right)$; and if $p^{F}=p^{R}$, then $\pi_{i}^{E F}\left(p^{F}\right)=\pi_{i}^{E R}\left(p^{R}\right)$.

Summarizing the above findings, we obtain the following proposition.

Proposition 2. In the case of non-drastic innovation, if conditions permit both fixed-fee licensing and royalty licensing, firm $i$ will consider production differentiation and technology spillover to make a choice between the two.

(i) For $d \in(0,0.7280)$, when $\beta<\bar{\beta}$, fixed-fee licensing is superior to royalty licensing; when $\beta>\bar{\beta}$, royalty licensing is superior to fixed-fee licensing; and when $\beta=\bar{\beta}$ or $\beta=1$, the two licensing policies are not different from one another.

(ii) For $d \in[0.7280,1)$, when $\beta<\hat{\beta}$, fixed-fee licensing is superior to royalty licensing; when $\beta \geq \hat{\beta}$, royalty licensing is superior to fixed-fee licensing; and when $\beta=1$, the two licensing policies are not different from one another.

Proposition 2 indicates that the advantages and disadvantages of the two licensing policies are closely related to product differentiation and technology spillover. Thus, compared with the above two policies, is two-part tariff licensing the best choice? A comparison between the two is required to answer this question.

\section{Comparison: Two-Part Tariff Licensing Versus Royalty Licensing}

When $\beta \geq 1-a d(2-d)^{2} / 2 c\left(4-3 d^{2}\right)$, two-part tariff licensing is equivalent to royalty licensing according to the analysis in subsection 4.3.2, and Proposition 2 has provided a comparison of royalty licensing and fixed-fee licensing.

When $\beta<1-a d(2-d)^{2} / 2 c\left(4-3 d^{2}\right)$, due to $1-a d(2-d)^{2} / 2 c\left(4-3 d^{2}\right)$

$1-(2-d)\left(4+2 d-d^{2}\right) a / 2 c\left(8-3 d^{2}\right)$, we must perform the analysis in two separate intervals according to Proposition 2, i.e.,

$$
\begin{aligned}
& \beta<1-(2-d)\left(4+2 d-d^{2}\right) a / 2 c\left(8-3 d^{2}\right) \text { and } \\
& 1-(2-d)\left(4+2 d-d^{2}\right) a / 2 c\left(8-3 d^{2}\right) \leq \beta< \\
& 1-a d(2-d)^{2} / 2 c\left(4-3 d^{2}\right) . \\
& \text { If } \\
& 1-(2-d)\left(4+2 d-d^{2}\right) a / 2 c\left(8-3 d^{2}\right) \leq \beta< \\
& 1-a d(2-d)^{2} / 2 c\left(4-3 d^{2}\right), \text { it is easy to verify that } \\
& p^{F R}-p^{R}=\frac{\left[(2-d)^{2} d a-2\left(4-3 d^{2}\right)(1-\beta) c\right]^{2}}{8\left(4-3 d^{2}\right)(2+d)^{2}(2-d)^{2} k}>0 \text { and } \\
& \pi_{i}^{E F R}(p)-\pi_{i}^{E R}(p)=\frac{p\left[(2-d)^{2} d a-2\left(4-3 d^{2}\right)(1-\beta) c\right]^{2}}{4\left(4-3 d^{2}\right)(2+d)^{2}(2-d)^{2}}>0 . \\
& \text { If } \beta<1-(2-d)\left(4+2 d-d^{2}\right) a / 2 c\left(8-3 d^{2}\right), \text { we have } \\
& p^{F R}-p^{R}=\frac{\left(8-8 d+d^{2}\right) a^{2}}{8\left(4-3 d^{2}\right) k}-\frac{[(2-d) a-2(1-\beta) c]^{2}}{2(2+d)^{2}(2-d)^{2} k}-\frac{\left[\left(4+2 d-d^{2}\right)^{2}+4\left(8-3 d^{2}\right)^{2}\right] a^{2}}{8\left(8-3 d^{2}\right)^{2}(2+d)^{2} k}
\end{aligned}
$$

Assuming that $p^{F R}-p^{R}>0$ is always true, we can simplify the above expression and obtain

$$
\begin{array}{r}
(2-d)^{2}\left[\left(8-8 d+d^{2}\right)\left(8-3 d^{2}\right)^{2}(2+d)^{2}-\left(4-3 d^{2}\right)\left(4+2 d-d^{2}\right)^{2}\right] a^{2} \\
+16\left(4-3 d^{2}\right)\left(8-3 d^{2}\right)(1-\beta) a c-16\left(4-3 d^{2}\right)(1-\beta)^{2} c^{2}>0(38)
\end{array}
$$

Because the innovation is non-drastic, $q_{j}^{s}=((2-d) a-2(1-\beta) c) /(2+d)(2-d)>0$, from which $a(2-d) a-2(1-\beta) c>0$ can be derived. Thus, $0<(1-\beta) c<a(2-d) / 2$. Therefore, as for the two solutions to the quadratic equation in $(1-\beta) c$, one should be less than 0 , and the other must be greater than $a(2-d) / 2$ (with the parabola pointing downwards). When $(1-\beta) c=0$, straightforward calculations show that Eq. (38)> 0 is permanently established. Therefore, it is true that one of the two solutions to the quadratic equation in $(1-\beta) c$ is always less than 0 . When $(1-\beta) c=(2-d) a / 2$, it is easy to verify that Eq. (38)> 0 is permanently established. Therefore, one solution is always greater than $(2-d) a / 2$. Thus, $p^{F R}-p^{R}>0$ is permanently established. To sum up, $p^{F R}-p^{R}>0$ if $\beta<1-(2-d)\left(4+2 d-d^{2}\right) a / 2 c\left(8-3 d^{2}\right)$.

Similar to the analysis above, it is easy to verify that the sign of $\pi_{i}^{E F R}(p)-\pi_{i}^{E R}(p)$ is the same as the sign of $p^{F R}-p^{R} \quad$ (i.e., $\quad \operatorname{sign}\left\{\pi_{i}^{E F R}(p)-\pi_{i}^{E R}(p)\right\}=\operatorname{sign}\left\{p^{F R}-p^{R}\right\} \quad$ ). Therefore, when $\beta<1-(2-d)\left(4+2 d-d^{2}\right) a / 2 c\left(8-3 d^{2}\right)$, $\pi_{i}^{E F R}(p)-\pi_{i}^{E R}(p)>0$ is permanently established.

In summary, if two-part tariff licensing is not equivalent to royalty licensing, the former is always superior to the latter. 


\section{Comparison: Two-Part Tariff Licensing Versus Fixed-Fee Licensing}

When $\beta \geq 1-a d(2-d)^{2} / 2 c\left(4-3 d^{2}\right)$, two-part tariff licensing is equivalent to royalty licensing according to subsection 4.3.2, and Proposition 2 provides a comparison between royalty licensing and fixed-fee licensing. Thus, we need to compare two-part tariff licensing with fixed-fee licensing when $\beta<1-a d(2-d)^{2} / 2 c\left(4-3 d^{2}\right)$.

It is easy to verify that

$$
p^{F R}-p^{F}=\frac{(2-d)^{4} d^{2} a^{2}}{8\left(4-3 d^{2}\right)(2+d)^{2}(2-d)^{2} k}>0
$$

$\pi_{i}^{E F R}(p)-\pi_{i}^{E F}(p)=\frac{p(2-d)^{4} d^{2} a^{2}}{4\left(4-3 d^{2}\right)(2+d)^{2}(2-d)^{2}}>0$. Therefore, if two-part tariff licensing is not equivalent to royalty licensing, the former is always superior to fixed-fee licensing.

To sum up, the following Proposition 3 and Proposition 4 can be made.

Proposition 3. In the case of a non-drastic innovation and regardless of the product differentiation of the two firms, when technology spillover is low $\left(\beta<1-a d(2-d)^{2} / 2 c\left(4-3 d^{2}\right)\right)$, the probability of occurrence of two-part tariff licensing is higher than that of the other two licensing policies; when technology spillover is high $\left(\beta \geq 1-a d(2-d)^{2} / 2 c\left(4-3 d^{2}\right)\right)$, two-part tariff licensing and royalty licensing will occur with the same probability.

From this proposition, we can see that the occurrence probability can serve as a reflection of the $R \& D$ investment with different licensing policies. Thus, in two-part tariff licensing, a high occurrence probability indicates comparatively high investment.

Proposition 4. In the case of a non-drastic innovation and regardless of the product differentiation of the two firms, when technology spillover is low $\left(\beta<1-a d(2-d)^{2} / 2 c\left(4-3 d^{2}\right)\right)$, two-part tariff licensing is superior to the other two licensing policies; when technology spillover is high $\left(\beta \geq 1-a d(2-d)^{2} / 2 c\left(4-3 d^{2}\right)\right)$, there is no difference between two-part tariff licensing and royalty licensing.

Proposition 4 indicates that in the case of non-drastic innovation, when the licensor has full bargaining power, two-part tariff licensing is superior to the other two means of licensing as long as the technology spillover is lower than the critical value (i.e., $\beta<1-a d(2-d)^{2} / 2 c\left(4-3 d^{2}\right)$ ), despite the product differentiation. In addition, the firm should decide its appropriate investment level according to its R\&D strength. When technology spillover is low (i.e., $\left.\beta<1-a d(2-d)^{2} / 2 c\left(4-3 d^{2}\right)\right)$, two-part tariff licensing is more likely to occur when investment is high.

\section{Conclusions}

In this paper, we discuss the optimal licensing strategy from the perspective of an inside innovator when the product market has a differentiated Cournot structure. The patentee has a patent on a cost-reducing innovation and optimizes his overall return by choosing fixed-fee licensing, royalty licensing or two-part tariff licensing. We develop a duopoly model with three stages, namely, the R\&D stage, the licensing stage and the output stage. We investigate the joint impact of R\&D outcome uncertainty and technology spillover on the optimal licensing strategy.

We have shown that (i) royalty licensing is always superior to no licensing regardless of the technology spillover and product differentiation (whether fixed-fee licensing and two-part tariff licensing will occur is related to technology spillover and product differentiation); (ii) if the conditions permit both fixed-fee licensing and royalty licensing, the innovating firm's choice will depend on the degree of technology spillover and product differentiation; and (iii) if the technology spillover is high, two-part tariff licensing is equivalent to royalty licensing. Otherwise, the patentee tends to license by means of a two-part tariff. Product differentiation does not influence the effectiveness of two-part tariff licensing.

Result (ii) is complementary to the result in (Wang, 2002), who compares fixed-fee licensing and royalty licensing in a differentiated Cournot duopoly model for an inside innovator and shows that royalty licensing may be superior to fixed-fee licensing. However, (Wang, 2002) fails to consider the effects of the uncertainty of R\&D outcomes and technology spillover on the innovator's licensing policy. Result (iii) provides possible theoretical explanations for the empirical observations in Rostoker (1984), who conducts a survey among 150 American companies regarding the use of technology licensing and finds that $13 \%$ of them license technology by means of a fixed fee, that $39 \%$ of them choose royalty licensing, and that two-part tariff licensing is adopted by $46 \%$ of the companies. The findings in this paper are consistent with the results of that survey in that two-part tariff licensing has an advantage over the other two licensing policies when technology spillover is low.

There are several interesting topics for further research illuminated in this paper. First, this paper assumes that the licensor has full bargaining power, which is not applicable in practice because the licensing fee is typically a compromise between the licensor and the licensee after bargaining. Future research can relax this assumption and explore licensing strategy decision-making with incomplete bargaining power. Second, we assume that there is only one firm conducting $R \& D$ and licensing its innovation in the technology market, which is contrary to the fact that many firms typically co-exist and compete with one another. Thus, one significant extension would be to consider how a number of firms simultaneously determine the optimal licensing strategy. Third, there is only one licensee in this paper. Therefore, another interesting extension to our research would be to investigate the effect of competition among multiple licensees on the optimal licensing strategy.

\section{Acknowledgements}

This research was supported in part by National Natural Science Foundation of China (Grant No. 71302005), the major Program of the National Social Science Fund of China (Grant No. 13\&ZD147), and Fundamental Research Funds 
for the Central Universities (Grant Nos. 2662014BQ048, 2662015PY176, 2662015QC050).

\section{Appendix}

Proof of Corollary 1. Licensing will occur only if $\Delta \pi_{i} \geq 0$ and $\Delta \pi_{j} \geq 0$. Thus, according to Eq. (11), fixed-fee licensing occurs if and only if $\Delta \pi_{i} \geq 0, \Delta \pi_{j} \geq 0 \Leftrightarrow \Delta \pi_{i}+\Delta \pi_{j} \geq 0$.

The following result can be derived by solving this inequality. $\beta \geq \beta_{1}^{*}=1-2 a(2-d)^{2} / c\left(4+d^{2}\right)$.

With firm $i$ undertaking a non-drastic innovation, if the R\&D is successful but licensing does not occur, the quantity for firm $j$ should be greater than 0, i.e., $((2-d) a-2(1-\beta) c) /(2+d)(2-d)>0$. Solving this inequality, we obtain $\beta>\beta_{0}=1-a(2-d) / 2 c$.

For $d \in(0,0.8284], \quad(2-d) / 2<2(2-d)^{2} /\left(4+d^{2}\right)$ and $\beta_{0}>\beta_{1}^{*} . \quad \beta \geq \beta_{1}^{*}$ is permanently established, and fixed-fee licensing will occur. For $d \in(0.8284,1], \beta_{0}<\beta_{1}^{*}$. In this condition, fixed-fee licensing will occur if and only if $\beta \geq \beta_{1}^{*}$.

Thus, Corollary 1 is proven. Q.E.D. The proofs of Corollaries 2 and 3 are similar to that of Corolly 1 , so we omit here.

Proof of Proposition 1. (i) For $\beta \geq 1-a(2-d)\left(4+2 d-d^{2}\right) / 2 c\left(8-3 d^{2}\right)$, we have

$$
\begin{gathered}
p^{F}-p^{R}=-\frac{\left(4-3 d^{2}\right)(1-\beta) c^{2}}{2(2+d)^{2}(2-d)^{2} k} \cdot\left\{\beta-\left[1-\frac{d(2-d)^{2}}{4-3 d^{2}} \cdot \frac{a}{c}\right]\right\}, \\
\pi_{i}^{E F}(p)-\pi_{i}^{E R}(p)=-\frac{\left(4-3 d^{2}\right)(1-\beta) c^{2}}{(2+d)^{2}(2-d)^{2}} \cdot\left\{\beta-\left[1-\frac{d(2-d)^{2}}{4-3 d^{2}} \cdot \frac{a}{c}\right]\right\} .
\end{gathered}
$$

Supposing that $p^{F}-p^{R}<0$ is true, we have $\beta>1-a d(2-d)^{2} /\left(4-3 d^{2}\right) c$.

If $d \in(0,0.7280)$, then $(2-d)\left(4+2 d-d^{2}\right) / 2\left(8-3 d^{2}\right)>d(2-d)^{2} /\left(4-3 d^{2}\right)$, and we can easily derive that $1-a(2-d)\left(4+2 d-d^{2}\right) / 2 c\left(8-3 d^{2}\right)<1-a d(2-d)^{2} /\left(4-3 d^{2}\right) c$. When $\beta<1-a d(2-d)^{2} /\left(4-3 d^{2}\right) c$, we have $p^{F}>p^{R}$; when $\beta>1-a d(2-d)^{2} /\left(4-3 d^{2}\right) c$, we have $p^{F}<p^{R}$.

If $d \in[0.7280,1)$, then $(2-d)\left(4+2 d-d^{2}\right) / 2\left(8-3 d^{2}\right) \leq d(2-d)^{2} /\left(4-3 d^{2}\right)$, and we can easily derive that $1-a(2-d)\left(4+2 d-d^{2}\right) / 2 c\left(8-3 d^{2}\right) \geq 1-a d(2-d)^{2} /\left(4-3 d^{2}\right) c$.

Hence, $\beta>1-a d(2-d)^{2} /\left(4-3 d^{2}\right) c$ is permanently established, and $p^{F}<p^{R}$ is proven.

(ii) For $\beta<1-a(2-d)\left(4+2 d-d^{2}\right) / 2 c\left(8-3 d^{2}\right)$, we have

$$
p^{R}-p^{F}=\frac{-(2-d)^{2}\left(20+2 d-7 d^{2}\right)\left(12-2 d-5 d^{2}\right) a^{2}+4\left(8-3 d^{2}\right)^{2}[(2-d) a-2(1-\beta) c]^{2}}{8\left(8-3 d^{2}\right)^{2}(2+d)^{2} k},
$$

$$
\pi_{i}^{E R}(p)-\pi_{i}^{E F}(p)=\frac{-(2-d)^{2}\left(20+2 d-7 d^{2}\right)\left(12-2 d-5 d^{2}\right) a^{2}+4\left(8-3 d^{2}\right)^{2}[(2-d) a-2(1-\beta) c]^{2}}{4\left(8-3 d^{2}\right)^{2}(2+d)^{2}} .
$$

Supposing that $p^{R}-p^{F}<0$ is true, then

$$
2\left(8-3 d^{2}\right)[(2-d) a-2(1-\beta) c]>(2-d) \sqrt{\left(20+2 d-7 d^{2}\right)\left(12-2 d-5 d^{2}\right)} \cdot a \text {. }
$$

Hence, $\beta<1-\left[\frac{2-d}{2}-\frac{(2-d) \sqrt{\left(20+2 d-7 d^{2}\right)\left(12-2 d-5 d^{2}\right)}}{4\left(8-3 d^{2}\right)}\right] \cdot \frac{a}{c}$.

Considering the precondition $\beta<1-a(2-d)\left(4+2 d-d^{2}\right) / 2 c\left(8-3 d^{2}\right)$, straightforward calculations show that $\frac{2-d}{2}-\frac{(2-d) \sqrt{\left(20+2 d-7 d^{2}\right)\left(12-2 d-5 d^{2}\right)}}{4\left(8-3 d^{2}\right)}<\frac{(2-d)\left(4+2 d-d^{2}\right)}{2\left(8-3 d^{2}\right)}$.

Therefore, $\beta<1-\left[\frac{2-d}{2}-\frac{(2-d) \sqrt{\left(20+2 d-7 d^{2}\right)\left(12-2 d-5 d^{2}\right)}}{4\left(8-3 d^{2}\right)}\right] \cdot \frac{a}{c}$ is permanently established.

Hence, $p^{F}>p^{R}$ is proven. Q.E.D.

\section{References}

Arora, A. (2009). The market for technology. Working Paper, Duke University.

Arora, A., Fosfuri, A., \& Ronde, T. (2013). Managing Licensing in a Market for Technology. Management Science 59(5), 1092-1106. http://dx.doi.org/10.1287/mnsc.1120.1628

Bagchi, A., \& Mukherjee, A. (2014). Technology licensing in a differentiated oligopoly. International Review of Economics and Finance 29, 455-465. http://dx.doi.org/10.1016/j.iref.2013.07.005

Chang, M. C., Hu, J. L., \& Lin, C. H. (2013). The optimal licensing strategy of an outside patentee in vertically-related markets. International Journal of Economics and Finance (5), 102-112. http://dx.doi.org/10.5539/ijef.v5n3p102

Chen, Y. W., Yang, Y. P., Wang, L. F. S., \& Wu, S. J. (2014). Technology licensing in mixed oligopoly. International Review of Economics and Finance 31, 193-204. http://dx.doi.org/10.1016/j.iref.2014.02.002

Colombo, S., \& Filippini, L. (2015). Patent licensing with Bertrand competitors. The Manchester School 83(1), 1-16. http://dx.doi.org/10.1111/manc. 12050 
Xianpei Hong, Qiang Lu, Lei Xu, Kannan Govindan, Ieva Meidute. Licensing Strategy for a Stochastic R\&D firm in ...

D'Aspremont, C., \& Jacquemin, A. (1988). Cooperative and noncooperative R\&D in duopoly with spillovers. American Economic Review (75), 1133-1137.

Erkal, N. (2005). Optimal licensing policy in differentiated industries. The Economic Record (81), 51-60. http://dx.doi.org/10.1111/j.1475-4932.2005.00216.x

Ferreira, F., \& Bode, O. R. (2013). Licensing endogenous cost-reduction in a differentiated Stackelberg model. Communications in Nonlinear Science and Numerical Simulation (18), 308-315. http://dx.doi.org/10.1016/ j.cnsns.2012.07.001

Ferreira, F., \& Bode, O. R. (2013). Licensing endogenous cost-reduction in a differentiated Stackelberg model. Communications in Nonlinear Science and Numerical Simulation 18(2), 308-315. http://dx.doi.org/10.1016/j. cnsns.2012.07.001

Filippini, L. (2005). Licensing Contract in a Stackelberg Model. The Manchester School (73), 582-598. http://dx.doi.org/10.1111/j.1467-9957.2005.00465.x

Gallini, N. T., \& Wright, B. D. (1990). Technology transfer under asymmetric information. Rand Journal of Economics (21), 147 -160. http://dx.doi.org/10.2307/2555500

Germerad, P. (2001). The changing role of R \& D. Reach-technology Management (44), 15-20.

Ghosh, A., \& Saha, S. (2015). Price competition, technology licensing and strategic trade policy. Economic Modelling 46, 91-99. http://dx.doi.org/10.1016/j.econmod.2014.09.014

Griliches, Z. (1992). The Search for R\&D Spillovers. The Scandinavian Journal of Economics 94 (supplement): S29-S47. http://dx.doi.org/10.2307/3440244

Kabiraj, T. (2005). Technology transfer in a Stackelberg structure: Licensing contracts and welfare. The Manchester School (73), 1-28. http://dx.doi.org/10.1111/j.1467-9957.2005.00421.x

Kamien, M. I., Oren, S. S., \& Tauman, Y. (1992). Optimal licensing of cost-reducing innovation. Journal of Mathematical Economics (21), 483-508. http://dx.doi.org/10.1016/0304-4068(92)90036-7

Kishimoto, S., Watanabe, N., \& Muto, S. (2011). Bargaining outcomes in patent licensing: Asymptotic results in a general Cournot market. Mathematical social sciences (61), 114-123. http://dx.doi.org/10.1016/j.mathsocsci.2010.12.001

Laursen, K., Leone, M. I., \& Torrisi, S. (2010). Technological exploration through licensing: new insights from the licensee's point of view. Industrial and Corporate Change 19, 871-897. http://dx.doi.org/10.1093/icc/dtq034

Leone, M. I., \& Reichstein, T. (2012). Licensing-in fosters rapid invention! The effect of the grant-back clause and technological unfamiliarity. Strategic Management Journal 33, 965-985. http://dx.doi.org/10.1002/smj.1950

Li, C. Y., \& Wang, J. M. (2010). Licensing a Vertical Product Innovation. Economic Record 86, $517-527$. http://dx.doi.org/10.1111/j.1475-4932.2010.00630.x

Lu, Y. Z., \& Poddar, S. (2014). Patent licensing in spatial models. Economic Modelling 42, $250-256$. http://dx.doi.org/10.1016/j.econmod.2014.06.016

Mansfield, E. (1985). How rapidly does new industrial technology leak out? Journal of Industrial Economics (34), 217-223. http://dx.doi.org/10.2307/2098683

Mittendorf, B., \& Arya, A. (2006). Enhancing vertical efficiency through horizontal licensing. Journal of Regulatory Economics (29), 333-342.

Mukherjee, A. (2010). Licensing a new product: Fee vs. royalty licensing with unionized labor market. Labor Economics (17), 735-742.

Mukherjee, A., \& Pennings, E. (2006). Tariffs, licensing and market structure. European Economic Review 50, $1699-1707$. http://dx.doi.org/10.1016/j.euroecorev.2005.08.005

Poddar, S., \& Sinha, U. B. (2002). The role of fixed fee and royalty in patent licensing. Working Paper, National University of Singapore.

Poddar, S., \& Sinha, U. B. (2010). Patent licensing from a high-cost firm to a low-cost firm. Economic Record (86), 384-395. http://dx.doi.org/10.1111/j.1475-4932.2010.00633.x

Rey, P., \& Salant, D. (2012). Abuse of dominance and licensing of intellectual property. International Journal of Industrial Organization (30), 518-527. http://dx.doi.org/10.1016/j.ijindorg.2012.05.003

Rockett, K. (1990). The quality of licensed technology. International Journal of Industrial Organization (8), $559-574$. http://dx.doi.org/10.1016/0167-7187(90)90030-5

Rostoker, M. (1984). A survey of corporate licensing. Journal of Law and Technology (24), 59-92.

Sen, D. (2005). On the coexistence of different licensing schemes. International Review of Economics and Finance (14), 393-413. http://dx.doi.org/10.1016/j.iref.2004.02.004

Tsai, K. H., Hsieh, M. H., \& Hultink, E. J. (2011). External technology acquisition and product innovativeness: The moderating roles of $\mathrm{R} \& \mathrm{D}$ investment and configurational context. Journal of Engineering and Technology Management 28(3), 184-200. http://dx.doi.org/10.1016/j.jengtecman.2011.03.005

Wang, K. C. A., Liang, W. J., \& Chou, P. S., (2013). Patent licensing under cost asymmetry among firms. Economic 
Modelling (31), 297-307. http://dx.doi.org/10.1016/j.econmod.2012.11.025

Wang, X. H. (2002). Fee versus royalty licensing in a differentiated Cornet duopoly. Journal of Economics \& Business (54), 253-266. http://dx.doi.org/10.1016/S0148-6195(01)00065-0

Wang, Y., Zhou, Z., Ning, L., \& Chen, J. (2015). Technology and external conditions at play: A study of learning-by-licensing practices in China. Technovation 43-44, 29-39. http://dx.doi.org/10.1016/j.technovation. 2015.03.006

Zhao, D., Chen, H. M., Hong, X. P., \& Liu, J. F. (2014). Technology licensing contracts with network effects. International Journal of Production Economics 158, 136-144. http://dx.doi.org/10.1016/j.ijpe.2014.07.023

The article has been reviewed.

Received in May, 2015; accepted in December, 2015. 